\title{
Organizational Intelligence: Antecedents And Consequences
}

Veli Denizhan Kalkan, Gebze Institute of Technology, Turkey

\begin{abstract}
This article seeks to conceptualize the construct of organizational intelligence with its antecedents and consequences and offer an overall view of organizational intelligence. It also makes a conceptual contribution to form the missing link between individual intelligence research and organizational intelligence studies. Based on a comprehensive literature review, a number of propositions are developed concerning the relationships of organizational intelligence with its antecedents and consequences. Then, a model is presented depicting the relationships proposed, and implications for future research and managerial practice are discussed. Suggested implications include a more significant managerial emphasis on improving organizational intelligence as well as increased attention to social and cultural aspects regarding the development of employees and organization, besides utilizing advanced information technologies.
\end{abstract}

\section{INTRODUCTION}

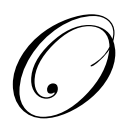

rganizational innovation is crucial for contemporary organizations to be competent in global markets. Implicitly stated in the literature, improving organizational intelligence is a prerequisite for enhancing innovation capability (Quinn, 1992; Nevis et al., 1995; Glynn, 1996; Teece et al., 1997; Romijn and Albaladejo, 2002; Akgün et al., 2003). Hence, the newly understood concept of organizational intelligence represents a new challenge for innovation practices of organizations and global business research. Organizational intelligence is briefly defined as the capability of an organization to generate knowledge and to use it strategically to adapt to its environment (McMaster, 1996; Halal, 1997). However, there is a lack of comprehensive studies on organizational intelligence. Psychological research on intelligence forms the basis of organizational intelligence studies (Glynn, 1996; Yolles, 2005). But the link between individual intelligence research and organizational intelligence studies is missing. This article seeks to make a contribution to form this link. Also, the organizational intelligence construct had not been conceptualized associated with its antecedents and consequences before. The article attempts to fill this gap and offer an overall view of organizational intelligence. Moving from an extensive literature review, the paper discusses and conceptualizes the components of the organizational intelligence construct with its antecedents and consequences. It develops propositions concerning the subject and offers a conceptual model of organizational intelligence that could be useful for future research. The paper concludes by discussing the implications of organizational intelligence challenge for managerial practice.

\section{BACKGROUND: PSYCHOLOGICAL RESEARCH ON INTELLIGENCE}

\section{Approaches to Intelligence}

The main source of organizational intelligence scholarship is psychological research on intelligence. Intelligence is vital in individuals' lives. However, it is a broad and elusive concept focusing on human cognitive abilities. In general, psychological literature conceptualized intelligence as information processing capacity that is used to solve problems and meet task challenges, briefly adapt to environment (Glynn, 1996). Recent psychological research examined the intelligence of the individual, sought the nature of intelligence and tried to define it (Sternberg and Detterman, 1986; Sternberg, 1997; Melis et al., 1999; Stankov, 2000; Shavinina, 2001; Buckhalt, 2002; Gottfredson, 2003; Brackett et al., 2004; Bates and Rock, 2004). Research also concentrated on types and/or components of intelligence and processes affecting intelligence (Sternberg and Kaufman, 1998; Bowman et al., 2002; Schlinger, 2003; Gottfredson, 2003). Actually, there are two major approaches to intelligence in the psychological 
literature: (1) A cognitive or psychometric perspective which focuses on intelligence as an individual trait called as general cognitive ability -or the g factor- (Herrnstein and Murray, 1994; Gottfredson, 1998), and (2) a contextualist perspective which views intelligence as composed of a number of interrelated but distinct abilities, and focuses on intelligence as a social product related to the cultural, normative web in which individuals are embedded (Vygotsky, 1978; Gardner, 1993, Glynn, 1996).

Both approaches have theoretical and practical advantages and restrictions. There is considerable empirical validation that general cognitive ability (g) imposed by the psychometric perspective is a significant predictor of job and career outcomes in organizational settings (O'Reilly and Chatman, 1994; Ree et al., 1995; Wright et al., 1995). However, the psychometric perspective has been faulted for being too limited and not inclusive of the full range of human activities that might be labeled intelligent (Glynn, 1996). Also it has been criticized for not considering how intelligence may be related to and defined by the social or cultural context in which it develops and functions (Glynn, 1996; Gardner, 2003). On the other hand, although it has been criticized for having a too relativistic character, contextual perspective can get a closer relationship with real life problems by considering intelligence as a construct composed of different components interacting reciprocally (Sternberg, 1984; Gardner, 1993). Taking the socio-cultural environment and its effects into account is another positive aspect of the view contextualist perspective offers (Vygotsky, 1978; Gardner, 2003).

\section{Emotional Intelligence}

The concept of emotional intelligence is one of the hottest topics of recent intelligence literature. It extends the idea of human cognitive abilities by proposing that emotional factors can affect intelligent behavior (Mayer et al., 2000a). Emotional intelligence is defined as the ability to identify, process and manage emotions of one's own and in others (Mayer et al., 2000b; Fox and Specter, 2000; Salovey and Pizarro, 2002; Van Rooy and Viswesvaran, 2004). The construct of emotional intelligence encompasses knowing what you are feeling and being able to handle those feelings without having them swamp you; being able to motivate yourself to get jobs done, being creative and performing at your peak; sensing what others are feeling, and handling relationships effectively (Mayer and Salovey, 1993; Dulewicz and Higgs, 2000). To be aware of feelings, to be able to manage them, motivate oneself, to conduct effective relationships by the help of empathy and social skills are based on emotional intelligence. The concept of emotional intelligence serves as a complementary tool to the traditional intelligence concept rather than expressing the opposite of it (Goleman, 1996). In addition to sufficient information and some technical skills, emotional intelligence is needed to cope with environmental demands and pressures (Martinez, 1997; Dulewicz and Higgs, 2000). A combination of classical intelligence criteria and emotional intelligence criteria explains more variation in outcome criteria than classical intelligence criteria alone (Dulewicz and Higgs, 2000). Emotional intelligence is not a static construct. It is regarded as a developable trait or competency (Goleman, 1996; Martinez, 1997).

\section{The Crossroad: Critical Points in the Literature}

The most important point the literature identifies is that the general cognitive ability $(\mathrm{g})$ concept, although proved to be useful for predicting individual outcomes in organizational settings, is unable to explain complex human activities and interactions. Especially in recent years, intensive critiques have risen against the explanatory view of general cognitive ability (Lubinski, 2000; Bowman et al., 2002; Schlinger, 2003). To evaluate which behaviors are intelligent and which are not depends on the essential understanding of the socio-cultural context of behaviors observed. And social complexity imposes that intelligence, like any other similar phenomena, should be evaluated as an integral concept composed of different components rather than an overarching capability. Therefore, the view of intelligence as having different components is becoming gradually prevalent (Sternberg, 1984; Mayer et al., 2000b; Schlinger, 2003; Gardner, 2003). Within the literature there is a strong consensus that intelligence encompasses the capacity of information processing and capability of adaptation to the environment (Sternberg \& Detterman, 1986; Glynn, 1996; Sternberg and Kaufman, 1998; Van Geert, 2002; Schlinger, 2003). The construct named as emotional intelligence is also evaluated within the integrity of intelligence (Gardner, 1999; Dulewicz and Higgs, 2000; Bowman et al., 2002; Quebbeman and Rozell, 2002). Therefore, the main components that must be considered as integrative parts of intelligence are information processing capacity, adaptive capability, and emotional intelligence 


\section{ORGANIZATIONAL INTELLIGENCE}

\section{The Concept Of Organizational Intelligence}

As a key driver of social and individual cognition, intelligence is an enabling force for performing mental and cognitive activities (Gottfredson, 1998; Sternberg et al., 2003). In addition to the individual level, intelligence is also important at the organizational level. Recently, it has been conceptualized as a critical capability of organizations (Leidner and Elam, 1995; Glynn, 1996; Akgün et al., 2003). Relatively new field of organizational intelligence is supported greatly by individual intelligence literature (Glynn, 1996; Yolles, 2005). Organizational intelligence definitions are generally developed based on individual intelligence perceptions and definitions. In his pioneering work, McMaster defines organizational intelligence as the capability to gather information from outside the organization to generate different market and technology scenarios, to interpret the environmental signals, to transfer customer needs to product design outcomes (McMaster, 1996). In general, organizational intelligence refers to the capacity of a corporation as a whole to gather information, to generate knowledge, and to act effectively based on the knowledge it has generated in order to adapt to the environment surrounding the organization (Nevis et al., 1995; Glynn, 1996; Halal, 1997; Schwaninger, 2001; Akgün et al., 2003). Intelligence is required for organizational learning to occur and organizational innovation to be generated (Cook and Yanow, 1993; Bonthous, 1996; Glynn, 1996). Therefore, an organization's intelligence is a key enabling force underlying many vital activities and processes dominating organizational life.

\section{Components Of Organizational Intelligence}

Organizations, like individuals, have multiple dimensions of competence (Albrecht, 2003; Stalinski, 2004). Therefore, organizational intelligence should be regarded as a construct composed of different components. Perception, cognition, memory, learning, communication, reasoning, culture, information processing and behavior flexibility are proposed as organizational intelligence components in the literature (Choo, 1995; McMaster, 1996; Halal, 1997; Erçetin, 2002). All these items are mainly related with technical, cultural and social aspects of information processing and adaptation to the environment. Thus, the main components of organizational intelligence that can be inferred at first sight are organizational information processing capacity and organizational adaptive capability. Organizational information processing capacity refers to the capacity of an organization to gather, interpret, share, synthesize and utilize information in the context of organizational experimentation (Tushman and Nadler, 1978; Thomas and McDaniel, 1990; Wang, 2003). Organizational adaptive capability implies that the organization can effectively respond to the environmental challenges. It refers to the ability of the organization to identify and capitalize emerging market and technology opportunities (Chakravarthy, 1982; Oktemgil and Greenley, 1997; Tuominen et al., 2004).

Scholars have described organizational intelligence as a social outcome generating from the interactions of the individuals in the organization in addition to the interaction of the organization and the environment (Choo, 1995; Glynn, 1996; Halal, 1997). Namely, intelligence plays its role in a social structure. Processes in and surrounding this social structure cannot be independent from human emotions (Domagalski, 1999; Vince, 2001; Akgün et al., 2003). Emotions are crucial not only for humans but also for organizations. The social foundation of an organization cannot exist without human emotions and feelings (Domagalski, 1999). It is composed of social relations and complex interactions which are profoundly influenced by both individual and collective emotions (Vince, 2001; Yang and Mossholder, 2004). The ability of an organization to deal effectively with the emotions expresses the collective emotional intelligence of that organization. Collective emotional intelligence is regarded as the organizational level analogue of individual emotional intelligence. It can be viewed as an emergent property originating from the individuals in the organization, amplified and crystallized by the complex interactions they are involved in, and manifested as a higher-level phenomenon (Morgeson and Hofmann, 1999; Yang and Mossholder, 2004). Consequently, in addition to information processing capacity and adaptive capability, collective emotional intelligence has to be regarded as a component of organizational intelligence. Proposition $1\left(\mathrm{P}_{1}\right)$ is therefore stated in the following terms: 
P1 Organizational intelligence is a multifaceted and multidimensional construct composed of organizational information processing capacity, organizational adaptive capability and collective emotional intelligence.

An organization is regarded as a system of intersubjectively shared meanings sustained through social interaction (Walsh and Ungson, 1991). Organizational intelligence emerges from those interactions that constitute the organization. It is embedded in the structured patterns of thought and action in which organizational members interact and engage (Glynn, 1996). Technologically advanced systems affect organizational intelligence as well. They enable the development of organizational intelligence (Huber, 1990; Leidner and Elam, 1995). Thus, organizational intelligence is more than the aggregate intelligence of organizational members; it is the intelligence of the organization itself as a larger system. An unintelligent organization can be composed of apparently intelligent people and an intelligent organization can be composed of relatively unintelligent components (Albrecht, 2003; Kerfoot, 2003). Organizations, as well as people, display differing degrees of intelligence. Differences among organizations' intelligences are not related to the differences among the intelligences of organizations' members only. Many factors such as organizational symbols, patterns of interaction, organizational culture, socialization processes and advanced technological systems influence the differences among organizations' intelligences. These factors form the organizational setting. Organizational setting is characterized by structural properties which are objective aspects of the organization and cannot be deduced from or reduced to the properties of organization members (Aiken et al., 1980). Some structural properties characterizing the organizational setting support organizational intelligence. These are the antecedents of organizational intelligence.

\section{ANTECEDENTS OF ORGANIZATIONAL INTELLIGENCE}

According to knowledge management and organizational change literatures; organizational slack, intention, autonomy, fluctuation and creative chaos, redundancy of information and requisite variety are regarded as factors enhancing information processing capacity, enabling knowledge creation and facilitating adaptation to the environment (Bourgeois, 1981; Chakravarthy, 1982; Nonaka and Takeuchi, 1995; Nohria and Gulati, 1996; Nonaka et al., 2000). Inspired by the approach of Staber and Sydow (2002), three variables -named multiplexity, redundancy and loose coupling- are considered as the antecedents of organizational intelligence. These variables encompass the concepts proposed earlier in the related literatures.

\section{Multiplexity}

Multiplexity - originally defined as the overlap of roles, exchanges, or affiliations in a social relationship (Verbrugge, 1979) - refers to the number and diversity of relations between actors in organizations (Staber and Sydow, 2002). Individuals employed in different departments of an organization have multiplex relations if they meet in different settings to discuss different issues related to the organization. For example, issues related to new product development can be discussed by the members of production and marketing departments. For organizational members, multiplexity facilitates the access to resources (Lazega and Pattison, 1999). A variety of resources may be exchanged this way and new ideas can be generated. This enhances the information processing capacity of the organization. Multiplexity creates a capacity for the evolution of a shared organizational mind (Morgan, 1997). It facilitates the rapid spread of information when it is needed. Thus, it supports organizational knowledge creation and so "enhances the organization's versatility in responding to volatile and fragmented demands from the environment" (Uzzi, 1996; Staber and Sydow, 2002). In this way, multiplexity improves the organization's adaptive capability.

\section{Redundancy}

Redundancy increases the diversity of organizational experimentation and enhances the ability of the organization to adapt to unknown environmental conditions (Bourgeois, 1981; Nonaka and Takeuchi, 1995; Greenley and Oktemgil, 1998). Redundancy must be evaluated in terms of the distribution of information, tasks and relations (Cohen and Levinthal, 1990; Staber and Sydow, 2002). Redundancy of information means that the organization has information that goes beyond the immediate operational requirements of organizational members (Nonaka and Takeuchi, 1995). Redundant information enhances the efficiency of information processing, promotes the sharing of tacit knowledge, speeds up the knowledge creation process and enhances the reliability of transmission (Cohen and 
Levinthal, 1990; Nonaka and Takeuchi, 1995). In an organization characterized by task redundancy, different elements of the system can accomplish a variety of functions (Staber and Sydow, 2002). Task redundancy helps to reduce operational gaps in the organization (Streeter, 1992). On the other hand, in an organization characterized by redundancy of relations, actors are linked in several ways, at least some of which carry the same information (Staber and Sydow, 2002). Redundancy of relations enhances the chance of utilizing alternative sources (Streeter, 1992; Staber and Sydow, 2002). In combination, redundancy of information, tasks and relations support information processing capacity and adaptive capability of the organization by making the organization more "error friendly" and more conducive to experimentation, learning, improvisation and risk taking (Staber and Sydow, 2002; Akgün et al., 2003).

\section{Loose Coupling}

Loose coupling in an organizational setting means that the various units, such as departments or strategic business units, and activities of the organization are relatively independent and can adjust to changing demands in different ways and at varying rates (Staber and Sydow, 2002). Loose coupling increases the organization's responsiveness to the challenging conditions imposed by the environment (Weick, 1995; Lengnick-Hall, 2004). In a loosely coupled organizational setting, units and activities have weak ties among each other. Weak ties are beneficial especially under conditions of uncertainty, when dealing with tacit knowledge and the application possibility of new knowledge is unclear (Cohen and Levinthal, 1990; Nonaka and Takeuchi, 1995). When organizational members, units and activities are weakly connected to each other, access to a broad range of information is provided. Though unintentionally, greater input from different organizational elements is obtained and fruitful insights can be yielded. Furthermore, new idea generation is triggered and so information processing capacity and adaptive capability is supported.

Multiplexity, redundancy and loose coupling support information processing capacity and adaptive capability as stated above. Literature strongly supports this. Besides this, literature also points to the role of emotions in most cognitive processes (Schwarz, 1998; Vince, 2001). Emotions are socially constructed and they interact reciprocally with information processing (Pratt and Barnett, 1997; Akgün et al., 2003). Complex interactions characterized by multiplexity, redundancy and loose coupling create opportunities to improve the understanding and management of emotions in the organization (Muchinsky, 2000; Sturdy, 2003). Therefore, social complexity in the organization supports collective emotional intelligence as well as information processing capacity and adaptive capability. In other words, the three structural properties of social complexity in the organization, the three antecedents as this study proposed, support collective emotional intelligence as well. It means that they support the improvement of organizational intelligence:

P2 Multiplexity, redundancy, and loose coupling in the organizational setting support the improvement of organizational intelligence.

\section{Redundancy}

Redundancy increases the diversity of organizational experimentation and enhances the ability of the organization to adapt to unknown environmental conditions (Bourgeois, 1981; Nonaka and Takeuchi, 1995; Greenley and Oktemgil, 1998). Redundancy must be evaluated in terms of the distribution of information, tasks and relations (Cohen and Levinthal, 1990; Staber and Sydow, 2002). Redundancy of information means that the organization has information that goes beyond the immediate operational requirements of organizational members (Nonaka and Takeuchi, 1995). Redundant information enhances the efficiency of information processing, promotes the sharing of tacit knowledge, speeds up the knowledge creation process and enhances the reliability of transmission (Cohen and Levinthal, 1990; Nonaka and Takeuchi, 1995). In an organization characterized by task redundancy, different elements of the system can accomplish a variety of functions (Staber and Sydow, 2002). Task redundancy helps to reduce operational gaps in the organization (Streeter, 1992). On the other hand, in an organization characterized by redundancy of relations, actors are linked in several ways, at least some of which carry the same information (Staber and Sydow, 2002). Redundancy of relations enhances the chance of utilizing alternative sources (Streeter, 1992; Staber and Sydow, 2002). In combination, redundancy of information, tasks and relations support information processing capacity and adaptive capability of the organization by making the organization more "error friendly" and 
more conducive to experimentation, learning, improvisation and risk taking (Staber and Sydow, 2002; Akgün et al., 2003).

\section{Loose Coupling}

Loose coupling in an organizational setting means that the various units, such as departments or strategic business units, and activities of the organization are relatively independent and can adjust to changing demands in different ways and at varying rates (Staber and Sydow, 2002). Loose coupling increases the organization's responsiveness to the challenging conditions imposed by the environment (Weick, 1995; Lengnick-Hall, 2004). In a loosely coupled organizational setting, units and activities have weak ties among each other. Weak ties are beneficial especially under conditions of uncertainty, when dealing with tacit knowledge and the application possibility of new knowledge is unclear (Cohen and Levinthal, 1990; Nonaka and Takeuchi, 1995). When organizational members, units and activities are weakly connected to each other, access to a broad range of information is provided. Though unintentionally, greater input from different organizational elements is obtained and fruitful insights can be yielded. Furthermore, new idea generation is triggered and so information processing capacity and adaptive capability is supported.

Multiplexity, redundancy and loose coupling support information processing capacity and adaptive capability as stated above. Literature strongly supports this. Besides this, literature also points to the role of emotions in most cognitive processes (Schwarz, 1998; Vince, 2001). Emotions are socially constructed and they interact reciprocally with information processing (Pratt and Barnett, 1997; Akgün et al., 2003). Complex interactions characterized by multiplexity, redundancy and loose coupling create opportunities to improve the understanding and management of emotions in the organization (Muchinsky, 2000; Sturdy, 2003). Therefore, social complexity in the organization supports collective emotional intelligence as well as information processing capacity and adaptive capability. In other words, the three structural properties of social complexity in the organization, the three antecedents as this study proposed, support collective emotional intelligence as well. It means that they support the improvement of organizational intelligence:

P2 Multiplexity, redundancy, and loose coupling in the organizational setting support the improvement of organizational intelligence.

\section{CONSEQUENCES OF ORGANIZATIONAL INTELLIGENCE}

The concept of intelligence is representative of some adaptive function having real-life consequences. The main consequence of organizational intelligence is related to organizational innovation. Organizational innovation represents the successful implementation of new ideas in the organization (Amabile et al., 1996; Versluis, 2005). It is composed of activities generating the new idea and transforming it to a new product/service or process having commercial and/or social value (Johannessen et al., 2001; Rose-Anderssen et al., 2005). Those activities involve the processes of knowledge acquisition, new organizational knowledge creation and knowledge utilization all of which require organizational intelligence. Additionally, organizational innovation requires fast and creative action under unaccustomed circumstances at the same time. This means that it requires organizational intelligence (Quinn, 1992; Glynn, 1996). In other words, intelligence underlies successful organizational innovation. The effects of organizational intelligence on organizational innovation process can be observed by means of the changes in innovation capability and organizational performance.

\section{Innovation Capability}

To examine the impact of a trait or process over organizational innovation process, the effects of the mentioned trait/process over innovation capability should be investigated. Because organizational innovation is a complicated process influenced by many factors inside and outside the organization, innovation may not be generated even though the investigated trait/process supports it. Thus, concentrating on innovation capability is more realistic and progressive. Innovation capability is at the core of organizational innovation. An organization's innovation capability refers to the ability of the organization to adopt or implement new ideas, processes, or products successfully (Burns and Stalker, 1961; Hurley and Hult, 1998). It is the potential of the organization to generate innovation and is 
highly contingent upon the level and types of internal and external resources and other competencies that the organization possesses (Calantone et al., 2002; Romijn and Albaladejo, 2002; Yam et al., 2004). The most important resources and competencies for innovation capability are the ones related to knowledge and learning (Romijn and Albaladejo, 2002; Cavusgil et al., 2003). Acquiring, processing and utilizing these resources and competencies depend on organizational intelligence (McMaster, 1996; Glynn, 1996; Schwaninger, 2001; Akgün et al., 2003). Improving organizational intelligence increases the utilization of the resources and competencies related to knowledge and learning, in this way supports innovation capability.

\section{Organizational Performance}

Organizations must be innovative to gain a competitive edge in order to survive. This requires a high level of organizational performance. Organizational performance indicates an organization's ability to form and meet economic goals of profitability, market share and so on (Gainer and Padanyi, 2005; Rahman and Bullock, 2005). In addition to financial criteria, social criteria may also be evaluated as organizational performance criteria in some cases (Rahman and Bullock, 2005). Innovation capability has been evaluated as the most important determinant of organizational performance (Mone et al., 1998; Calantone et al., 2002; Yam et al., 2004). Because realizing opportunities, utilizing resources and other competencies in order to benefit from opportunities and meet task challenges are impossible without innovation capability. Empirical studies support the positive relationship between organizational innovation capability and organizational performance (Cooper, 2000; Calantone et al., 2002; Guan and Ma, 2003; Yam et al., 2004). Organizational intelligence effects organizational performance positively via enhancing innovation capability. So, though the effect is indirect, improving organizational performance should be evaluated as a critical consequence of organizational intelligence:

P3 . Organizational intelligence enhances organizational performance via fostering organizational innovation capability.

\section{DISCUSSION AND IMPLICATIONS}

Organizational intelligence, with its antecedents and consequences, represents a continuous cycle of activities that include sensing the environment, using memory about past experience to help perceptions, developing perceptions, improving interpretations, generating meaning through interpretations and taking action based on the interpretations developed. This process is called the organizational intelligence cycle (Choo, 1995; Halal, 1997; Halal, 2002). However, in the literature, organizational intelligence cycle had not been conceptualized as regarding the components jointly with antecedents and consequences. Figure 1 offers a fresh and more comprehensive view of the organizational intelligence cycle.

In this conceptual paper, prior studies in related literatures are reviewed to offer a basic framework of organizational intelligence. Figure 1 illustrates the basic conceptual model of organizational intelligence. In contrast with the previous literatures, the model does not focus on the various activities realized throughout the organizational intelligence cycle; rather it depicts the critical components of the cycle. Concentrating on these components will prove beneficial for organizational intelligence scholarship. The foremost limitation of organizational intelligence scholarship is that it is currently at the conceptual stage of development. Organizational intelligence studies should consider developing more complicated models and empirically testing the propositions offered. Future research should also consider concentrating on other aspects of organizational intelligence, especially its role in organizational learning process. Besides all, the limitations of propositions/inferences offered by this paper are indeed important. For instance; negative aspects of redundancy and other organizational intelligence antecedents, and the extent to which they support organizational intelligence must be considered and investigated.

Managerial practice should focus on improving organizational intelligence in order to survive. All dimensions of organizational intelligence need to be developed. Organizational intelligence is much more than information processing capacity. Hence, the focus should not be on the use of advanced information technologies only. Social and 
cultural aspects regarding the development of employees and organization should be considered. To foster innovation, managers must be able to influence motivational and situational factors improving intelligence. Human resource

Figure 1
Antecedents Organizational Intelligence Components
Consequences

A Conceptual Model of Organizational Intelligence

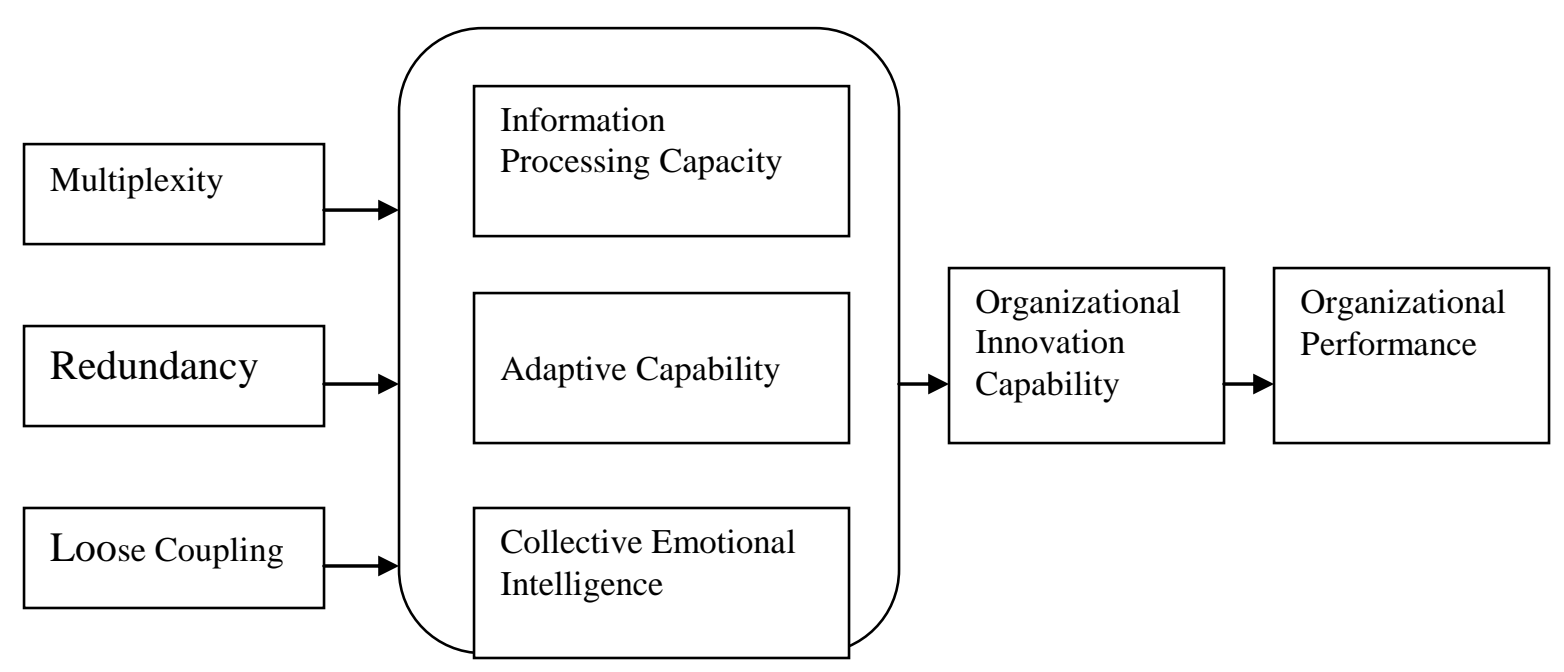

specialists might play an important role to facilitate the process by sharing their knowledge and expertise regarding human relations in the organization. Intelligent behavior should be encouraged by incentives. Lack of collective emotional intelligence may harm technically successful projects and processes via preventing the full potential outcomes of them from being realized. So, managers must pay attention to developing emotional intelligence in the organization. Organizational intelligence components, especially collective emotional intelligence, are crucial for global business organizations having diverse work forces and surrounded by complex socio-cultural environments. Global business managers must target improving organizational intelligence by executing appropriate supportive interventions to organizational culture, strategy, and structure. In order to realize this, before all else, managers should accept the challenge to build the infrastructure that leads to improvement in organizational intelligence and promote multiplexity, redundancy and loose coupling in the organization.

\section{REFERENCES}

1. Aiken, M., Bacharach, S. B., \& French, J. L. (1980). Organizational structure, work processes and proposal making in administrative bureaucracies. Academy of Management Journal, 23, 631-652.

2. Akgün, A. E., Lynn, G. S., \& Byrne, J. C. (2003). Organizational learning: A socio-cognitive framework. Human Relations, 56, 839-868.

3. Albrecht, K. (2003). The power of minds at work: Organizational intelligence in action. New York, NY: AMACOM.

4. Amabile, T. M., Conti, R., Coon, H., Lazaenby, J., \& Herron, M. (1996). Assessing the work environment for creativity. Academy of Management Journal, 39, 1154-1184.

5. Bates, T. C. \& Rock, A. (2004). Personality and information processing speed: Independent influences on intelligent performance. Intelligence, 32, 33-46.

6. $\quad$ Bonthous, J. M. (1996). Intelligence as learning. Competitive Intelligence Review, 7, S49-S59.

7. $\quad$ Bourgeois, L. (1981). On the measurement of organizational slack. Academy of Management Review, 6, 2939.

8. Bowman, D. B., Markham, P. M. \& Roberts, R. D. (2002). Expanding the frontier of human cognitive abilities: So much more than (plain) g! Learning and Individual Differences, 13, 127-158. 
9. Brackett, M. A., Mayer, J. D. \& Warner, R. M. (2004). Emotional intelligence and its relation to everyday behavior. Personality and Individual Differences, 36, 1387-1402.

10. Buckhalt, J. A. (2002). A short history of g: psychometrics' most enduring and controversial construct. Learning and Individual Differences, 13, 101-114.

11. Burns, T. \& Stalker, G. M. (1961). The management of innovation. London, UK: Tavistock Publishing.

12. Calantone, R. J., Cavusgil, S. T. \& Zhao, Y. (2002). Learning orientation, firm innovation capability, and firm performance. Industrial Marketing Management, 31, 515-524.

13. Cavusgil, S. T., Calantone, R. J. \& Zhao, Y. (2003). Tacit knowledge transfer and firm innovation capability. The Journal of Business and Industrial Marketing, 18, 6-21.

14. Chakravarthy, B. S. (1982). Adaptation: A promising metaphor for strategic management. Academy of Management Review, 7, 35-44.

15. Choo, C. W. (1995). Information management for an intelligent organization: The art of environmental scanning. Medford, NJ: Learned Information.

16. Cohen, W. M. \& Levinthal, D. A. (1990). Absorptive capacity: A new perspective on learning and innovation. Administrative Science Quarterly, 35, 128-152.

17. Cook, S. D. N. \& Yanow, D. (1993). Culture and organizational learning. Journal of Management Inquiry, 2, 373-390.

18. Cooper, R. G. (2000). New product performance: What distinguishes the star products. Australian Journal of Management, 25, 17-45.

19. Domagalski, T. A. (1999). Emotions in organizations: Main currents. Human Relations, 52, 833-852.

20. Dulewicz, V. \& Higgs, M. (2000). Emotional intelligence: A review and evaluation study. Journal of Managerial Psychology, 15, 341-372.

21. Erçetin, Ş. Ş. (2002). Action research...organizational intelligence...curriculum development. Educational Research Quarterly, 26, 41-49.

22. Fox, S. \& Specter, P. E. (2000). Relations of emotional intelligence, practical intelligence, general intelligence and trait affectivity with interview outcomes: It's not all just ' $\mathrm{g}$ '. Journal of Organizational Behavior, 21, 203-220.

23. Gainer, B. \& Padanyi, P. (2005). The relationship between market-oriented activities and market-oriented culture: Implications for the development of market orientation in nonprofit service organizations", Journal of Business Research, 58, 854-862.

24. Gardner, H. (1993). Frames of mind. New York, NY: Basic Books.

25. Gardner, H. (1999). Who owns intelligence? The Atlantic Monthly, 283, 67-76.

26. Gardner, H. (2003, April). Multiple intelligences after twenty years. Paper presented at the American Educational Research Association Congress, Chicago, Illinois. $21^{\text {st }}$ April 2003. Available online (April $10^{\text {th }}$, 2005): http://pzweb.harvard.edu/PIs/HG_MI_after_20_years.pdf

27. Glynn, M. A. (1996). Innovative genius: A framework for relating individual and organizational intelligences to innovation. Academy of Management Review, 21, 1081-1111.

28. Goleman, D. (1996). Emotional intelligence: Why it can matter more than IQ. London, UK: Bloomsbury Publishing.

29. Gottfredson, L. S. (1998). The general factor of intelligence. Scientific American, 9, 24-29.

30. Gottfredson, L. S. (2003). Dissecting practical intelligence theory: Its claims and evidence. Intelligence, 31, 343-397.

31. Greenley, G. \& Oktemgil, M. (1998). A comparison of slack resources in high and low performing British companies. Journal of Management Studies, 35, 377-398.

32. Guan, J. \& Ma, N. (2003). Innovative capability and export performance of Chinese firms. Technovation, 23, 737-747.

33. Halal, W. E. (1997). Organizational intelligence. Strategy \& Business, 9, 10-13.

34. Halal, W. E. (2002). Tracking technology. On the Horizon-The Strategic Planning Resource for Education Professionals, 10, 1-5.

35. Herrnstein, R. J. \& Murray, C. (1994). The bell curve: Intelligence and class structure in American life. New York, NY: Free Press.

36. Huber, G. (1990). A theory of the effects of advanced information technologies on organizational design, intelligence and decision making. Academy of Management Review, 15, 47-71. 
37. Hurley, R. F. \& Hult, G. T. M. (1998). Innovation, market orientation, and organizational learning: An integration and empirical examination. Journal of Marketing, 62, 42-54.

38. Kerfoot, K. (2003). Organizational intelligence/organizational stupidity: The leader's challenge. Nursing Economics, 21, 91-93.

39. Lazega, E. \& Pattison, P. E. (1999). Multiplexity, generalized exchange and cooperation in organizations: A case study. Social Networks, 21, 67-90.

40. Leidner, D. E. \& Elam, J. J. (1995). The impact of executive information systems on organizational design, intelligence, and decision making. Organization Science, 6, 645-664.

41. Lengnick-Hall, C. A., Lengnick-Hall, M. L., \& Abdinnour-Helm, S. (2004). The role of social and intellectual capital in achieving competitive advantage through enterprise resource planning (ERP) systems. Journal of Engineering and Technology Management, 21, 307-330.

42. Lubinski, D. (2000). Scientific and social significance of assessing individual differences: Sinking shafts at a few critical points. Annual Review of Psychology, 51, 405-444.

43. Martinez, M. N. (1997). The smarts that count. HR Magazine, 42, 72-78.

44. Mayer, J. D. \& Salovey, P. (1993). The intelligence of emotional intelligence. Intelligence, 17, 433-442.

45. Mayer, J. D., Salovey, P. \& Caruso, D. R. (2000a). Models of emotional intelligence. In R. J. Sternberg (Ed.), Handbook of intelligence (pp. 396-420). New York, NY: Cambridge University Press.

46. Mayer, J. D., Caruso, D. R., \& Salovey, P. (2000b). Emotional intelligence meets traditional standards for an intelligence. Intelligence, 27, 267-298.

47. McMaster, M. D. (1996). The intelligence advantage: Organizing for complexity. Newton, MA: ButterworthHeinemann.

48. Melis, C., Van Boxtel, A. \& Hettema, J. (1999). Generalizability of component processes in intelligence as revealed by latency measures. Intelligence, 27, 45-81.

49. Mone, M. A., McKinley, W., \& Barker, V. L. (1998). Organizational decline and innovation: A contingency framework. Academy of Management Review, 23, 115-32.

50. Morgan, G. (1997). Images of organization ( $2^{\text {nd }}$ Edition). Thousand Oaks, CA: Sage Publications.

51. Morgeson, F. P. \& Hofmann, D. A. (1999). The structure and function of collective constructs: Implications for multilevel research and theory development. Academy of Management Review, 24, 249-65.

52. Muchinsky, P. M. (2000). Emotions in the workplace: The neglect of organizational behavior. Journal of Organizational Behavior, 21, 801-805.

53. Nevis, E. C., Dibella, A. J. \& Gould, J. M. (1995). Understanding organizations as learning systems. Sloan Management Review, 36, 73-85.

54. Nohria, N. \& Gulati, R. (1996). Is slack good or bad for innovation? Academy of Management Journal, 39, 1245-1264.

55. Nonaka I. \& Takeuchi, H. (1995). The knowledge-creating company. New York, NY: Oxford University Press.

56. Nonaka, I., Toyama, R. \& Konno, N. (2000). SECI, ba and leadership: A unified model of dynamic knowledge creation. Long Range Planning, 33, 5-34.

57. O'Reilly, C. A. \& Chatman, J. A. (1994). Working smarter and harder: A longitudinal study of managerial success. Administrative Science Quarterly, 39, 603-627.

58. Oktemgil, M. \& Greenley, G. (1997). Consequences of high and low adaptive capability in UK companies. European Journal of Marketing, 31, 445-466.

59. Pratt, M. G. \& Barnett, C. K. (1997). Emotions and unlearning in Amway recruiting techniques. Management Learning, 28, 65-88.

60. Quebbeman, A. J. \& Rozell, E. J. (2002). Emotional intelligence and dispositional affectivity as moderators of workplace aggression: The impact on behavior choice. Human Resource Management Review, 12, $125-43$.

61. Quinn, J. B. (1992). Intelligent enterprise: A knowledge and service-based paradigm for industry. New York, NY: Free Press.

62. Rahman, S. \& Bullock, P. (2005). Soft TQM, hard TQM, and organizational performance relationships: An empirical investigation. Omega, 33, 73-83.

63. Ree, M. J., Carretta, T. R., \& Teachout, M. S. (1995). Role of ability and prior job knowledge in complex training performance. Journal of Applied Psychology, 80, 721-730. 
64. Romijn, H. \& Albaladejo, M. (2002). Determinants of innovation capability in small electronics and software firms in southeast England. Research Policy, 31, 1053-1067.

65. Rose-Anderssen, C., Allen, P. M., Tsinopoulos, C., \& McCarthy, I. (2005). Innovation in manufacturing as an evolutionary complex system. Technovation, 25, 1093-1105.

66. Salovey, P. \& Pizarro, D. A. (2002). The value of emotional intelligence. In R. J. Sternberg, J. Lautrey, \& T. I. Lubart (Eds.), Models of intelligence: International perspectives (pp. 263-78). Washington, DC: American Psychological Association.

67. Schlinger, H. D. (2003). The myth of intelligence. The Psychological Record, 53, 15-32.

68. Schwaninger, M. (2001). Intelligent organizations: An integrative framework. Systems Research and Behavioral Science, 18, 137-158.

69. Schwarz, N. (1998). Warmer and more social: Recent developments in cognitive social psychology. Annual Review of Sociology, 24, 239-264.

70. Shavinina, L. V. (2001). Beyond IQ: A new perspective on the psychological assessment of intellectual abilities. New Ideas in Psychology, 19, 27-47.

71. Staber, U. \& Sydow, J. (2002). Organizational adaptive capacity: A structuration perspective”, Journal of Management Inquiry, 11, 408-424.

72. Stalinski, S. (2004). Organizational intelligence: A systems perspective. Organization Development Journal, 22, 55-67.

73. Stankov, L. (2000). Structural extensions of a hierarchical view on human cognitive abilities. Learning and Individual Differences, 12, 35-51.

74. Sternberg, R. J. (1984). Toward a triarchic theory of human intelligence. Behavior and Brain Sciences, 7, 269-315.

75. Sternberg, R. J. (1997). Successful intelligence: How practical and creative intelligence determine success in life. New York, NY: Plume.

76. Sternberg, R. J. \& Detterman, D. K. (1986). What is intelligence? Contemporary viewpoints on its nature and definition. Norwood, NJ: Ablex Publishing Corporation.

77. Sternberg, R. J. \& Kaufman, J. C. (1998). Human abilities. Annual Review of Psychology, 49, 479-502.

78. Sternberg, R. J., Lautrey, J. \& Lubart, T. I. (2003). Where are we in the field of intelligence, how did we get here, and where are we going? In R. J. Sternberg, J. Lautrey, \& T. I. Lubart (Eds.), Models of intelligence: International perspectives (pp. 3-25). Washington, DC: American Psychological Association.

79. Streeter, C. L. (1992). Redundancy in organizational systems. Social Service Review, 66, 97-111.

80. Sturdy, A. (2003). Knowing the unknowable? A discussion of methodological and theoretical issues in emotion research and organizational studies. Organization, 10, 81-105.

81. Teece, D. J., Pisano, G., \& Shuen, A. (1997). Dynamic capabilities and strategic management. Strategic Management Journal, 18, 509-533.

82. Thomas, J. B. \& McDaniel, R. R. (1990). Interpreting strategic issues: Effects of strategy and the information-processing structure of top management teams. Academy of Management Journal, 33, 286-306.

83. Tuominen, M., Rajala, A. \& Möller, K. (2004). How does adaptability drive firm innovativeness? Journal of Business Research, 57, 495-506.

84. Tushman, M. L. \& Nadler, D. A. (1978). Information processing as an integrating concept in organizational design. Academy of Management Review, 3, 613-624.

85. Uzzi, B. (1996). The sources and consequences of embeddedness for the economic performance of organizations. American Sociological Review, 61, 674-698.

86. Van Geert, P. (2002). Measuring intelligence in a dynamic systems and contextualist framework. In R. J. Sternberg, J. Lautrey, \& T. I. Lubart (Eds.), Models of intelligence: International perspectives (pp. 195-211). Washington, DC: American Psychological Association.

87. Van Rooy, D. L. \& Viswesvaran, C. (2004). Emotional intelligence: A meta-analytic investigation of predictive validity and nomological net. Journal of Vocational Behavior, 65, 71-95.

88. Verbrugge, L. M. (1979). Multiplexity in adult friendships. Social Forces, 57, 1286-1309.

89. Versluis, C. (2005). Innovations on thin ice. Technovation, 25, 1183-1192.

90. Vince, R. (2001). Power and emotion in organizational learning. Human Relations, 54, 1325-1351.

91. Vygotsky, L. S. (1978). Mind in society: The development of higher psychological processes, Cambridge, MA: Harvard University Press. 
92. Walsh, J. P. \& Ungson, G. R. (1991). Organizational memory. Academy of Management Review, 16, 57-91.

93. Wang, E. T. G. (2003). Effect of the fit between information processing requirements and capacity on organizational performance. International Journal of Information Management, 23, 239-247.

94. Weick, K. E. (1995). Sensemaking in organizations. Thousand Oaks, CA: Sage Publications.

95. Wright, P. M., Kacmar, K. M., McMahan, G. C., \& Deleeuw, K. (1995). P=F(Mxa): Cognitive ability as a moderator of the relationship between personality and job performance. Journal of Management, 21, 11291139.

96. Yam, J. C., Guan, J. C., Pun, K. F. \& Tang, E. P. Y. (2004). An audit of technological innovation capabilities in Chinese firms: Some empirical findings in Beijing, China. Research Policy, 33, 1123-1140.

97. Yang, J. \& Mossholder, K. W. (2004). Decoupling task and relationship conflict: The role of intragroup emotional processing. Journal of Organizational Behavior, 25, 589-605.

98. Yolles, M. (2005). Organisational intelligence. The Journal of Workplace 